\title{
O farelinho de trigo fermentado com Bacta-Mon e excremento de vaca na alimentação de píntos
}

\author{
A. P. TRIVELIN
}

E. S. A. "Luiz de Queiroz" 


\section{1 - INTRODUÇÃO}

O Bacta-mon é um produto distribuído pela Indústria e Comércio Bacta-mon S. A., São Paulo, como adubo microbiológico e como suplemento nutritivo e estimulante para os animais.

Segundo ROSTON (1957), encerra linhagens dos fungos Rhizopus elegans, Mucor plumbeus e Aspergillus oryzae e da levedura Hansenula anomala, sleecionados e resistentes à temperatura de $50^{\circ} \mathrm{C}$ e aos ácidos fracos. Apresenta-se sob a forma de um farelo, contendo pequena porcentagem de argila e grande quantidade de esporos dos fungos e da levedura citados.

Experimentos, realizados por SALIM (1959), empregando o Bacta-mon como adubo para alface, cenoura e rabanete, não revelaram efeitos favoráveis quando comparados com o estêrcó de curral.

Sendo recomendado como nutritivo e estimulante para animais, elaboramos o presente trabalho, empregando-o na alimentação de pintos, a fim de verificarmos a possibilidade de melhorar uma ração normalmente balanceada.

\section{2 - MATERIAL E MetODOS}

\section{1 - Fermentação do farelinho de trigo}

O emprêgo do Bacta-mon não é feito na forma como é vendido. Segundo as instruções recebidas, foi realizada a fermentação do farelinho de trigo, entrando aquêle produto na proporção de $1 \%$.

A mistura foi umedecida com água até o ponto em que revelava ligeiro grau de aglutinação. A homogeneização, após o umedecimento, foi feita inicialmente com auxílio de uma pá, e por fim com um forcado, para melhor desfazer os torrões. A seguir, foi amontoada para fermentar, e coberta com uma armação de madeira, fechada com sacos, para proteger contra a evaporação.

Paralelamente a êste trabalho, foi feita também a fermentação do mesmo alimento, com fezes frescas de vaca, diluídas em água. A quantidade de fezes empregada foi de $20 \%$, isto é, 5 quilos de excremento para 20 de farelinho. Além da diluição das fezes em água, esta foi adicionada em quantidade suficiente para conseguir ligeiro grau de aglutinação. 
Após seu revolvimento foi amontoada e coberta com sacos vazios e deixada a fermentar.

$\mathrm{Em}$ ambos os casos a fermentação teve a duração de 14 dias, e as misturas foram revolvidas 2 vêzes, no $3 .^{\circ}$ e no $8 .^{\circ}$ dia, para facilitar o seu arejamento. As temperaturas foram tomadas nos dias subseqüentes à instalação, em 2 ou 3 pontos diferentes, a uma altura aproximada de $1 / 3$ do chão, com auxílio de um termômetro de mercúrio em vidro de indicação instantânea.

Durante os 8 primeiros dias foram tomadas 3 vêzes ao dia, pela manhã (às 8,30 horas), durante o dia (às 12,30 horas) e pela tarde (entre 16 e 16,30 horas), e durante os 4 dias seguintes apenas duas vêzes, pela manhã e pela tarde, e nos últimos 2 dias de fermentação, sòmente pela manhã.

No primeiro dia de fermentação, as temperaturas médias, constatadas nas misturas com Bacta-mon e com excremento, foram respectivamente $49,6^{\circ} \mathrm{C}$ e $32^{\circ} \mathrm{C}$, e que estas se elevaram sempre até o $80^{\circ}$ dia, quando se registraram as temperaturas máximas que foram as seguintes: $62^{\circ} \mathrm{C}$ e $58,2^{\circ} \mathrm{C}$. Dêsse $80^{\circ}$ dia as temperaturas passaram a decrescer paulatinamente $e^{\prime}$ no $14 .^{\circ}$, que foi o último dia de fermentação, foram registradas respectivamente $30^{\circ} \mathrm{C}$ e $25^{\circ} \mathrm{C}$. As temperaturas registradas na fermentação com o Bacta-mon foram um pouco mais elevadas que aquelas constatadas na fermentação com o excremento de vaca, e gràficamente seriam representadas por 2 curvas pràticamente paralelas.

O farelinho fermentado com o Bacta-mon apresentou uma coloração clara, de cheiro agradável, enquanto o fermentado com o excremento de vaca revelou-se mais escuro e de odor algo desagradável.

\section{2 - Experimento}

Foram formados 4 lotes de pintos correspondendo a 4 tratamentos, respectivamente com 50, 50, 49 e 48 cabeças, conforme se pode observar no Quadro III, os quais foram pesados semanalmente. Em cada lote entraram 3 raças a saber - New Hampshire, Leghorn Branca e White American - em número pràticamente igual, correspondendo cada raça a uma repetição. No início do experimento os pintos contavam com alguns dias de idade.

Os lotes assim constituídos foram colocados em uma bateria e estiveram, durante o tempo em que durou o experimento, submetidos às mesmas condições de trato, apenas diferindo pela ração fornecida. 
As rações utilizadas estão no Quadro I. Foi considerado para comparação uma ração balanceada $R 1$; substituiu-se nessa ração $10 \%$ do farelinho de trigo por igual pêso do produto fermentado pelo Bacta-mon (ração R2), com a finalidade de averiguar a possibilidade de melhorar a ração testemunha empregada. Em duas outras rações, R3 e R4, fêz-se a supressão da farinha de carne, mantendo-se contudo o nível protéico mais ou menos constante. Nelas foram introduzidas respectivamente, em substituição, a $10 \%$ de farelinho de trigo, igual pêso de farelinho de trigo fermentado pelo Bacta-mon e pelas fezes de vaca. No início do experimento não se sabia da riqueza em Ca e $\mathrm{P}$ dos produtos fermentados, de maneira que, com a substituição do farelinho de trigo e com a supressão da farinha de carne, a relação $\mathrm{Ca} / \mathrm{P}$ nas rações não se mostraram pràticamente as mesmas. Não obstante, isto possa constituir uma falha, não é de tal gravidade, a ponto de afetar o resultado do experimento. Segundo as recomendações do Conselho Nacional de Pesquisas dos EE.UU. para aves, citadas por MORRISON (1956), as exigências em Ca e $P$ para pintos de 0-8 semanas são, respectivamente, de $1 \%$ e de $0,6 \%$, e as rações utilizadas satisfazem essas condições.

Foi feita também a introdução de Delsterol e de sulfato de manganês para prevenir a possibilidade de avitaminose D e de aparecimento de perose.

Com 15 dias de experimento, os pintos passaram a receber sol e verde à vontade, uma vez ao dia.

$O$ produto utilizado neste experimento foi gentilmente ofertado pela firma produtora BACTA-MON S. A., São Paulo,

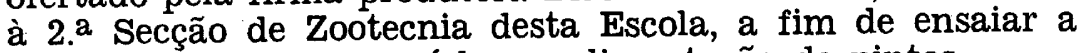
possibilidade de empregá-lo na alimentação de pintos.

\section{3 - ANÁlise, RESUltados E DISCUSSÃO}

Para análise da variância foi empregado o teste Teta de Brieger e para comparação das médias, o teste de TUKEY e de SCHEFF'

No Quadro III estão reunidos os aumentos médios de pêso verificados nas pesadas inicial e final (sexta pesada) e os aumentos médios totais determinados pela diferença entre estas pesadas.

A análise da variância dos aumentos médios totais, reunida no Quadro V, mostra para os tratamentos (rações) e para as repetições (raças), significância estatística para o limite de $1 \%$ de probabilidade. 
Empregando o teste de TUKEY, o tratamento R1 não apresentou diferença estatística quando foi comparado ao R2, donde se deduz que a inclusão do farelinho de trigo fermentàdo com Bacta-Mon' à ração balanceada testemunha não surtiu efeito. Comparando o tratamento R1 com os R3 e R4, o teste acusou respectivamente significância para o limite de $5 \%$, porém próximo de $1 \%$ na primeira comparação e para 0 limite de $1 \%$, na segunda. $\mathrm{O}$ tratamento $\mathrm{R2}$ relativamente ao R3, apresentou significância estatística para o nível de $1 \% \mathrm{e}$, como êles apenas diferem pela farinha de carne, pode-se concluir que esta diferença seja determinada pela falta de proteína animal.

Os tratamentos R3 e R4 quáando comparados entre si não revelaram diferença estatística o que mostra que o farelinho de trigo fermentado pelo Bacta-Mon e pelo excremento de vaca, apresentaram efeitos semelhantes, quando incorporados à ração sem proteína animal.

O teste de SCHFF́ aplicado a esta primeira parte da análise, apresentou resultados idênticos. O tratamento R1, podendo ser considerado semelhante ao R2 e o R3 ao R4, procurou-se por êste teste comparar os 2 primentos (R1 + R2) com o terceiro (R3) e os 2 primeiros com os 2 últimos $(\mathrm{R} 3+\mathrm{R} 4)$. Em ambos os casos foi constatada significância estatística para o limite de $1 \%$ de probabilidade o que permite concluir que o principal efeito foi determinado pela ausência da farinha de carne, confirmando assim a conclusão anterior.

No Quadro IV estão reunidos os aumentos médios semanais e a análise da variância dêsses dados é encontrada no Quadro VII.

Segundo o teste Teta, os aumentos médios semanais e os tratamentos (rações) apresentaram significância estatística para o limite de 1\% de probabilidade. As repetições (raças) dentro das pesadas revelaram-se significativas para o nível de $1 \%$. O teste de TUKEY e o de SCHEFFE, aplicados a esta parte da análise, confirmaram plenamente as conclusões chegadas.

A mortalidade verificada e o gasto de ração constatados, incluindo as perdas inevitáveis durante o experimento, estão reunidos no Quadro VII. Tem-se nítida impressão que os dados observados em R1 e R2 podem ser considerados normais, enquanto que aquêles registrados nos tratamentos R3 e R4, são bem distintos dos dois primeiros tratamentos e podem ser considerados anômalos. 
A maior mortalidade ocorrida e o menor consumo de ração verificado nos tratamentos R3 e R4, permitem supor que a ausência de proteína animal tenha contribuído para isso, e que, provàvelmente, o farelinho de trigo fermentado pelo Bacta-mon e pelas fezes de vaca, tenham conferido menor palatabilidade à ração.

E interessante ressaltar que as fezes de vaca colhidas frescas, secas ao sol e moídas, quando incorporadas a uma ração para pintos, na proporção de $2 \%$, substituem satisfatòriamente a farinha de carne, conforme experimento realizado por BERGAMIN (1951). Os resultados chegados no presente trabalho permitem concluir que a fermentação tenha sido prejudicial, embora fôssem as fezes de vaca, na forma fresca, entradas, em proporção de $20 \%$.

\section{4 - RESUMO E CONCLUSOES}

O produto empregado no presente experimento é vendido comercialmente pela Firma Bacta-mon S. A., São Paulo, como adubo microbiológico. Segundo ROSTON (1957), encerra linhaǵens de 3 fungos - Rhizopus elegans, Mucor plumbeus e Aspergillus oryzae, e de uma levedura - Hansenula anomala, selecionadas e resistentes à temperatura de $50^{\circ} \mathrm{C}$ e aos ácidos fracos.

O A., estudando a possibilidade de utilizá-lo na alimentação de pintos, formou 4 lotes, os quais receberam as rações R1, R2, R3 e R4, encontradas no Quadro I. Entraram na constituição de cada lote 3 raças - New Hampshire, Leghorn Branca e White American - em número pràticamente igual, que para efeito da análise estatística foram consideradas como repetições.

O Bacta-mon foi empregado fermentando o farelinho de trigo. Paralelamente a esta fermentação, foi feita uma outra, utilizando o mesmo subproduto do trigo e as fezes frescas de vaca, na proporção de $20 \%$, diluídas em água. Em ambos os casos a fermentação durou 14 dias, apresentando o produto fermentado pelo Bacta-mon coloração clara, cheiro agradável, enquanto que, o fermentado pelas fezes de vaca, coloração mais escura e de cheiro algo desagradável. As análises químicas do Bacta-mon e dos produtos fermentados são encontrados no Quadro II.

Durante todo o tempo (42 dias) que durou o experimento, os 4 lotes estiveram submetidos às mesmas condições de trato, apenas diferindo pela ração recebida. 
Os aumentos de pêso verificados estão nos Quadros III e IV e a análise da variância em V e VI. $O$ gasto verificado de ração, incluindo as perdas normais, e a mortalidade constatada são encontrados em VII.

Os testes empregados foram o de TUKEY e de SCHEFF', e as conclusões podem ser assim resumidas:

(a) - O farelinho de trigo fermentado pelo Bacta-mon, quando incorporado na proporção de $10 \%$, substituindo igual pêso daquele subproduto de trigo, na ração testemunha $\mathbf{R} 1$, não apresentou efeito, visto os aumentos de pêso não revelarem significância estatística.

(b) - A diferença estatística constatada quando se comparou a ração $\mathrm{R} 2$ contendo $10 \%$ de farelinho de trigo fermentado com Bacta-mon, com a ração sem farinha de carne, e contendo $10 \%$ do mesmo produto fermentado, pode ser atribuida exclusivamente à falta de proteína de origem animal.

(c) - Embora em números absolutos, os aumentos de pêso verificados com a ração $R 3$, sem farinha de carne e com farelinho de trigo fermentado com Bacta-mon, fôssem um pouco maiores que os aumentos registrados com a ração $R 4$, sem farinha de carne, contendo farelinho fermentado com excremento de vaca, estatìsticamente, são considerados semẹlhantes.

(d) A sobra verificada de ração e a mortalidade ocorrida durante o experimento permitem concluir que o maior efeito não foi determinado pròpriamente pela incorporação dos produtos fermentados à ração sem farinha de carne, e sim pela supressão da proteína de origem animal, e que provàvelmente, contribuiram para dar menor palatabilidade à ração.

\section{5 - AGRADECIMENTO}

O A. agradece ao Prof. Guido Ranzani, pela autorização concedida para a confecção da análise química do Bacta-mon e dos produtos fermentados empregados no experimento; ao analista Armando Porta pela confecção da referida análise química; ao Prof. Frederico Pimentel Gomes, pela orientação dada à parte da análise estatística; e ao Prof. A. P. Torres, pelas críticas e sugestões apresentadas durante a realização do experimento. 


\section{6 - ABSTRACT}

Bacta-mon, produced by Bacta-mon S. A., São Paulo, Brazil, is recommended as a microbiological, and suggested as a supplement for animal rations.

This experiment deals with this product in chicken feeding. Four lots of baby chicken received, during 6 weeks the following treatments: a control ration $\mathrm{R} 1$; a ration $\mathrm{R} 2$ containing 10 per cent of wheat standard middlings fermented by Bacta-mon, substituting equal weight of wheat standard middlings of the control ration $\mathrm{R} 1$; two rations $\mathrm{R} 3$ and $R 4$, both without meat meal and containing 10 per cent of wheat standard middlings fermented respectively by Bactamon and fresh cow manure, substituting equal weight of wheat standard middlings of the control.

The results may be so summarized:

(1) On the basis of the weights of the chicks at 6 weeks age, we concluded that there was not any advantage in the addition of the wheat standard middlings fermented by Bacta-mon.

(2) The rations $R 3$ and R4 were considered statistically equivalents and lower the control ration $\mathrm{R} 1$.

(3) It seems that the main difference observed in these results may be atributed to lack of animal protein.

(4) The highest mortality and the lowest consumption of feed by the lots receiving ration $\mathrm{R3}$ and $\mathrm{R4}$, seem to indicate, in addition, that this prejudice was due the lack of animal protein and the unpalatability of these rations.

\section{7 - BIBLIOGRAFIA CITADA}

BERGAMIN, A., 1951 - O Excremento de Vaca na Alimentação de Pintos em Crescimento. Anais da E. S. A. "Luiz de Queiroz", 8: 687-691.

PIMENTEL GOMES, F., 1955 - Curso de Estatística Experimental. Parte I - Experimentos Simples. Curso lecionado na. E. S. A. "Luiz de Queiroz". Mimeog. 63. Piracicaba.

MORRISON, F. B., 1956 - Feeds and Feeding. $22 .^{a}$ ed. Unabridged. The Morrison Publishing Company. Ithaca. New York. $1165 \mathrm{p}$.

ROSTON, J. J., 1957 - O "Bacta-mon". São Paulo. 30 pp.

SIMÃO, SALIM, 1959 - Ensaio de Adubação com o Bacta-mon. 7.0 Congresso Brasileiro de Clência do Solo. E. S. A. "Luiz de Queiroz". Piracicaba. 
QUADRO I

RAÇÕES UTILIZADAS

\begin{tabular}{|c|c|c|c|c|}
\hline \multirow{2}{*}{ INGREDIENTES } & \multicolumn{4}{|c|}{ LOTE S } \\
\hline & $\mathbf{R}_{1}$ & $\mathbf{R}_{2}$ & $\mathbf{R}_{\mathbf{3}}$ & $\mathbf{R}_{4}$ \\
\hline & quilos & quilos & quilos & quilos \\
\hline Milho $\ldots \ldots \ldots \ldots$ & 40 & 40 & 40 & 40 \\
\hline Farinha de carne $(50 \%)$ & 9 & 9 & - & - \\
\hline Farelo de algodão .... & 9 & 9 & 13,5 & 13,5 \\
\hline Farelo de amendoim ... & 9 & 9 & 13,5 & 13,5 \\
\hline Farelo grosso de trigo . & 10 & 10 & 10 & 10 \\
\hline Farelo fino de trigo .. & 20 & 10 & 10 & 10 \\
\hline $\mathrm{Bm} \quad \ldots \ldots \ldots \ldots \ldots$ & - & 10 & 10 & - \\
\hline $\mathbf{B v} \quad \ldots \ldots \ldots \ldots \ldots$ & - & 一 & - & $10^{\prime}$ \\
\hline Farinha de ossos .... & 1 & 1 & 1 & 1 \\
\hline Farinha de ostra .... & 1,5 & 1,5 & 1,5 & 1,5 \\
\hline Sal $\ldots \ldots \ldots \ldots$ & 1 & 1 & 1 & 1 \\
\hline Delsterol & 0,015 & 0,015 & 0,015 & 0,015 \\
\hline MnS O $\ldots \ldots \ldots \ldots$ & 0,015 & 0,015 & 0,015 & 0,015 \\
\hline Proteina bruta ...... & $20,1 \%$ & $20,4 \%$ & $19,4 \%$ & $19,2 \%$ \\
\hline Relação $\mathrm{Ca} / \mathrm{P} \ldots . .$. & $1,6: 1$ & $1,5: 1$ & $1,2: 1$ & $1,3: 1$ \\
\hline
\end{tabular}

Bm - farelinho de trigo fermentado com Bactc-Mon.

Bv - farelinho de trigo fermentado com fezes frescas de vaca. 
QUADRO II

ANÁLISE QUIMICA REALIZADA NO LABORATORIO DA 13. a CADEIRA - AGRICULTURA GERAL DA ESCOLA SUPERIOR DE AGRICULTURA "LUIZ DE QUEIROZ"

\begin{tabular}{|c|c|c|c|}
\hline . & Bacta-Mon & $\begin{array}{l}\text { Bacta-Mon e } \\
\text { Farelinho de trigo } \\
\text { (fermentado) }\end{array}$ & $\begin{array}{c}\text { Excremento de } \\
\text { Vaca e Farelinho } \\
\text { de Trigo } \\
\text { (fermentado) }\end{array}$ \\
\hline Umidade $\ldots \ldots \ldots \ldots \ldots$ & $11,290 \%$ & $13,160 \%$ & $14,790 \%$ \\
\hline Cinza $\ldots \ldots \ldots \ldots \ldots \ldots$ & $24,790 \%$ & $10,940 \%$ & $9,060 \%$ \\
\hline Fibra bruta $\ldots \ldots \ldots \ldots$ & $21,148 \%$ & $14,867 \%$ & $16,803 \%$ \\
\hline Matéria graxa ....... & $6,050 \%$ & $1,041 \%$ & $0,937 \%$ \\
\hline Proteinas $\ldots \ldots \ldots \ldots$ & $17,848 \%$ & $19,223 \%$ & $17,371 \%$ \\
\hline Ext. não azotados . . & $18,874 \%$ & $40,769 \%$ & $41,039 \%$ \\
\hline Elementos minerais da Cinza: & & & \\
\hline P2 O5 & $3,210 \%$ & $3,210 \%$ & $2,741 \%$ \\
\hline $\mathrm{CaO}$ & $0,210 \%$ & $0,269 \%$ & $0,731 \%$ \\
\hline
\end{tabular}


Quadro III

AUMENTO MEDIO DE PESO VERIFICADO DURANTE O EXPERIMENTO

\begin{tabular}{|c|c|c|c|c|c|}
\hline & \multirow{2}{*}{ Raças } & \multicolumn{4}{|c|}{ L O T E S } \\
\hline & & $\mathbf{R}_{1}$ & $\mathbf{R}_{2}$ & $\mathbf{R}_{\mathbf{3}}$ & $\mathbf{R}_{\mathbf{4}}$ \\
\hline Pesada inicial & $\begin{array}{l}\text { NH } \\
\text { L } \\
\text { WA }\end{array}$ & $\begin{array}{l}\text { gr. } \quad \mathrm{n} \\
53,4(19) \\
45,9 \text { (19) } \\
51,8 \text { (12) }\end{array}$ & $\begin{array}{lc}\text { gr. } & \mathrm{n} \\
51,7 & (19) \\
48,9 & (19) \\
50,7 & (12)\end{array}$ & $\begin{array}{cc}\text { gr. } & \text { n } \\
52,1 & (19) \\
46,4 & (19) \\
53,3 & (11)\end{array}$ & $\begin{array}{l}\text { gr. } \quad \text { n } \\
51,4(19) \\
47,8(17) \\
50,3(12)\end{array}$ \\
\hline $\begin{array}{l}\text { Pesada final } \\
\left(6 .^{\mathrm{a}} \text { semana) }\right.\end{array}$ & $\begin{array}{l}\text { NH } \\
\text { L } \\
\text { WA }\end{array}$ & $\begin{array}{l}575,0(19) \\
355,0(19) \\
513,5(10)\end{array}$ & $\begin{array}{l}570,6(18) \\
406,2(17) \\
489,6(12)\end{array}$ & 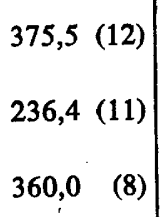 & $\begin{array}{l}282,1 \quad(12) \\
234,6 \quad(13) \\
351,9 \quad(8)\end{array}$ \\
\hline $\begin{array}{c}\text { Aumento de pêso } \\
\text { verificado durante as } 6 \\
\text { semanas de experimento }\end{array}$ & $\begin{array}{l}\text { NH } \\
\text { L } \\
\text { WA }\end{array}$ & $\begin{array}{l}521,6 \\
309,1 \\
461,7\end{array}$ & $\begin{array}{l}518,9 \\
357,3 \\
438,9\end{array}$ & $\begin{array}{l}323,4 \\
190,0 \\
306,7\end{array}$ & $\begin{array}{l}230,7 \\
186,8 \\
301,6\end{array}$ \\
\hline
\end{tabular}


QUADROS IV

AUMENTO MEDIO DE PESO

(Gramas)

\begin{tabular}{|c|c|c|c|c|c|}
\hline \multirow{2}{*}{$\begin{array}{l}\text { Período } \\
\text { considerado }\end{array}$} & \multirow{2}{*}{ Raças } & \multicolumn{4}{|c|}{ L O T E S } \\
\hline & & $\mathbf{R}_{\mathbf{4}}$ & $\mathbf{R}_{\mathbf{3}}$ & $\mathbf{R}_{\mathbf{2}}$ & $\mathbf{R}_{1}$ \\
\hline \multirow{3}{*}{ 1. ${ }^{\mathrm{a}}$ Semana } & NH & 42,5 & 43,4 & 32,4 & 35,9 \\
\hline & $\mathbf{L}$ & 23,7 & 29,4 & 22,5 & 29,5 \\
\hline & WA & 32,2 & 31,9 & 33,5 & 33,5 \\
\hline \multirow{3}{*}{ 2. ${ }^{a}$ Semana } & NH & 73,4 & 79,5 & 44,0 & 54,0 \\
\hline & $\mathbf{L}$ & 42,7 & 54,1 & 32,1 & 39,8 \\
\hline & WA & 64,9 & 65,8 & 44,7 & 66,8 \\
\hline \multirow{3}{*}{ 3. ${ }^{\mathrm{a}}$ Semana } & NH & 94,1 & 103,9 & 41,7 & 56,0 \\
\hline & $\mathbf{L}$ & 53,0 & 70,7 & 44,6 & 48,1 \\
\hline & WA & 82,4 & 90,9 & 64,7 & 77,1 \\
\hline \multirow{3}{*}{ 4. ${ }^{a}$ Semana } & NH & 113,7 & 116,5 & 68,6 & 48,9 \\
\hline & $\mathbf{L}$ & 64,4 & 79,5 & 30,2 & 52,3 \\
\hline & WA & 101,7 & 103,6 & 43,8 & 83,7 \\
\hline \multirow{3}{*}{ 5. ${ }^{a}$ Semana } & NH & 87,8 & 81,8 & 39,1 & 2,7 \\
\hline & $\mathbf{L}$ & 39,5 & 52,5 & 31,2 & $-10,0$ \\
\hline & WA & 109,2 & 65,7 & 45,4 & $-7,4$ \\
\hline \multirow{3}{*}{ 6. ${ }^{a}$ Semana } & NH & 110,1 & 94,5 & 97,6 & 33,2 \\
\hline & $\mathbf{L}$ & 85,8 & 71,1 & 29,4 & 27,1 \\
\hline & WA & 71,3 & 81,0 & 74,6 & 47,9 \\
\hline
\end{tabular}


QUADRO V

ANÁLISE DA VARIÂNÇA

CONSIDERANDO O AUMENTO MEDIO DE PESO VERIFICADO DURANTE O EXPERIMENTO

\begin{tabular}{|c|c|c|c|c|c|}
\hline C. da Var. & G. L. & S. Q. & Q. M. & Erro & Teta \\
\hline Rações . & 3 & $96.891,45$ & $32.297,15$ & 179,6 & $4,33 * *$ \\
\hline Raças & 2 & $44.021,91$ & $22.010,96$ & 148,4 & $3,58 * *$ \\
\hline Rações $\times$ Raças $\ldots$. & 6 & $10.321,61$ & $1.720,27$ & 41,5 & \\
\hline Total & 11 & $151.234,97$ & & & \\
\hline
\end{tabular}

QuADRo VI

ANĀLISE DA VARIANÇA

CONSIDERANDO OS AUMENTOS MEDIOS SEMANAIS DE PESO

\begin{tabular}{|c|c|c|c|c|c|}
\hline C. da Variação & G. L. & S. Q. & Q. M. & Erro & Teta \\
\hline Pesadas $\ldots .$. . & 5 & $16.478,05$ & $3.295,61$ & 57,40 & $2,17 * *$ \\
\hline Rações & 3 & $16.148,58$ & $5.382,86$ & 73,36 & $2,75 * *$ \\
\hline Pesadas $\times$ Rações & 15 & $10.648,68$ & 709,91 & 26,64 & $2,17 * * *$ \\
\hline Sub-Total ...... & 23 & $43.275,31$ & & & \\
\hline Raças dentro das pesadas & 12 & $8.858,02$ & 738,17 & 27,17 & $2,22 * * *$ \\
\hline Resíduo & 36 & $5.401,29$ & 150,04 & 12,25 & \\
\hline Total $\ldots \ldots \ldots$ & 71 & $57.534,62$ & & & \\
\hline
\end{tabular}




\begin{tabular}{l} 
QUADRO VII \\
CONSUMO DE RAÇÃO E NUMERO DE MORTES \\
OCORRIDO DURANTE O PERIODO EXPERIMENTAL (42 DIAS) \\
\hline \\
\hline
\end{tabular}

